\title{
Methamphetamine lowers self-stimulation thresholds
}

\author{
SOLOMON S. STEINER* and SUSAN N. STOKELY† \\ Department of Pharmacology, Schering Corporation, Bloomfield, New Jersey 07003
}

\begin{abstract}
According to Stein (1964a), amphetamines exert their effect on behavior by lowering neural reward thresholds. An alternative explanation is that amphetamines simply increase low rates of response. The present paper indicates that methamphetamines do, in fact, lower thresholds for self-stimulation. This is not an artifact produced by a generalized increase in response rate, since equated response rates at opposite ends of the intensity continuum were changed in different directions by the drug. The alternative explanation would predict that equated response rates should be changed in the same direction by the drug. Amphetamines were also shown to decrease variability at intensities which were around threshold prior to drug treatment. This is interpreted as being additive evidence that the drug is lowering threshold.
\end{abstract}

While researchers agree that amphetamines exert powerful effects on self-stimulation behavior, considerable disagreement exists over both the nature and the theoretical explanation for these effects. Horovitz, Chow, and Carlton (1962), Olds (1959), and Stein (1964c) have demonstrated an increase in response rates for intracranial stimulation (ICS) following administration of amphetamine. Stein $(1964 a, b)$ accounts for this effect by postulating that amphetamine acts specifically to lower neural reward thresholds. An alternative interpretation of Stein's data explains the increase in response rates for ICS following administration of amphetamine without postulating any specific action on reward thresholds. Dews and Morse (1961) and McMillan (1968) have demonstrated that pigeons working for a food reward will show changes in their response rates under the influence of amphetamine which are a function of their control rates of responding. These investigators maintain that the effects of amphetamine on all behavior are a function of the control rate of responding and the dosage. Low rates of responding are readily increased over a wide range of amphetamine doses. Very high response rates, while not affected by small doses, are decreased by large doses of amphetamines (McMillan, 1968). While this alternative interpretation is not in itself a theoretical explanation (it does not offer an explanation as to why amphetamine has this effect), it casts serious doubt on Stein's (1964a) conceptualization of neural reward mechanisms. Dews's (1958) interpretation suggests that the increase in response rate for ICS seen under amphetamine is a nonspecific action not necessarily related to neural reward thresholds. This paper attempts to distinguish between these two interpretations by making use of the inverted-U rate-intensity functions generated by

*Now at the Department of Psychology. City College of the City University of New York.

†Now at the Institute for Behavioral Research, Inc.. Silver Spring, Maryland. self-stimulating rats with electrodes in the lateral hypothalamic area (Olds, 1956; Reynolds, 1958; Bower \& Miller, 1958). If Dews's (1958) suggestion is correct, all low response rates, regardless of intensity of stimulation, should increase under amphetamine. Conversely, all high response rates should decrease under amphetamine. On the other hand, if amphetamine lowers the neural thresholds, then the entire rate-intensity function should be shifted to the left.

With an inverted- $U$ rate-intensity. function, it is possible to equate response rates at both low and high stimulation intensities. If the control rate of responding is the critical variable in determining the effects of amphetamine on behavior, then all equated response rates, regardless of the stimulation intensity, should change in the same direction under drug treatment: low response rates should show an increase and high response rates should show a decrease. If, however, amphetamine lowers neural reward thresholds, as Stein (1964a) suggests, equal response rates generated at opposite ends of the intensity continuum should be differentially affected by the drug: response rates maintained by low-intensity stimulation should be increased, while equivalent response rates maintained by high-intensity stimulation should be decreased.

\section{METHOD}

\section{Subjects}

Nine male albino Charles River rats, each weighing approximately $250 \mathrm{~g}$ at the start of the study, were used as Ss. Bipolar insulated stainless steel electrodes, bared of insulation at the tips, were implanted in each rat, with the use of a stereotaxic device, while the $S$ was under sodium pentobarbital and chloral hydrate anesthesia. The electrodes were aimed at hypothalamic structures that in the past have yielded self-stimulation effects.

\section{Intracranial Stimulation Parameters}

Biphasic rectangular waves were used. Each pulse pair consisted of two $0.2-\mathrm{msec}$ waves that were opposite in polarity and separated by an interval of $0.2 \mathrm{msec}$. Pulse pairs were 
Table 1

Average Response Rate Per Minute Expressed as a Ratio of Controls for Low and High Intensities of Stimulation Under Different Dosages of Methamphetamine

\begin{tabular}{|c|c|c|c|c|c|c|c|c|}
\hline \multirow{3}{*}{$\begin{array}{l}\text { Animal } \\
\text { Number }\end{array}$} & \multicolumn{8}{|c|}{ Dose of Methamphetamine $\mathrm{HCl}$} \\
\hline & \multicolumn{2}{|c|}{$0.5 \mathrm{mg} / \mathrm{kg}$} & \multicolumn{2}{|c|}{$1.11 \mathrm{mg} \mathrm{kg}$} & \multicolumn{2}{|c|}{$2.0 \mathrm{mg} / \mathrm{kg}$} & \multicolumn{2}{|c|}{$4.0 \mathrm{mg} / \mathrm{kg}$} \\
\hline & Low I & High I & Low I & High I & Low I & High I & Low I & High I \\
\hline 40 & 20.00 & 0.39 & - & - & 43.00 & 0.39 & - & - \\
\hline 83 & 11.50 & 1.03 & 5.00 & 0.88 & 9.00 & 0.70 & 26.00 & 0.09 \\
\hline 84 & 17.83 & 0.82 & - & - & - & - & - & - \\
\hline 87 & 1.33 & 0.86 & 2.03 & 0.82 & 2.98 & 0.26 & 2.89 & 0.13 \\
\hline 96 & 4.50 & 0.38 & 5.29 & 0.39 & 1.38 & 0.35 & 8.60 & 0.33 \\
\hline 97 & 1.18 & 1.67 & 1.25 & 1.85 & .02 & $0.03_{c}$ & $0.03_{c}$ & $0.04_{c}$ \\
\hline 99 & 6.00 & 1.43 & 5.71 & 0.11 & - & - & $0.03_{\mathrm{c}}$ & $0.01_{c}$ \\
\hline $5 \mathrm{~A}$ & 1.53 & 0.73 & 4.50 & 0.40 & 6.30 & 0.26 & $0.10_{\mathrm{c}}$ & $0.02_{\mathrm{c}}$ \\
\hline $11 \mathrm{~A}$ & 1.67 & 0.75 & - & - & - & - & $0.05_{\mathrm{c}}$ & $0.03_{c}$ \\
\hline
\end{tabular}

CIndicates coniulsions occurring during drug treatment.

Vote-I = intensity. Scores of 1.0 indicate no change: scores greater than 1.0 indicate an increase in response rate during drug treatment: scores less than 1.0 indicate a decrease in response rate during drug treatment.

delivered at a frequency of $100 / \mathrm{sec}$. and train duration was held constant at $0.25 \mathrm{sec}$. Stimulation intensity (current) was varied according to the demands of the experiment and was continuously monitored on an oscilloscope.

\section{Experimental Procedure}

After a minimum of 10 days following surgery. Ss were shaped to self-stimulate on a lever in a sound-deadened experimental chamber. The range of current intensities that would support responding on a continuous reinforcement schedule (CRF) was explored. At least six intensities were selected from this range. The criteria for selecting these intensities insured that the highest intensities tested would not produce gross motor artifacts or convulsions and that the lowest intensities would not support consistent responding on a CRF schedule. In addition, a zero-intensity control was also run. The Ss were allowed to self-stimulate for $10 \mathrm{~min}$ at each intensity daily. The intensities were presented in a different order each day. On a given day, high and low intensities were alternated. Responses per minute were recorded and printed automatically.

Data collected in the last $5 \mathrm{~min}$ of a 10 -min test period were averaged and plotted as a function of intensity. Rate-intensity functions so generated were replicated at least five times for any given $S$ prior to drug testing.

Drug treatment consisted of intraperitoneal injections of either normal saline or $0.5,1.0,2.0$. or $4.0 \mathrm{mg}$ of methamphetamine $\mathrm{HCl}$ per kilogram of body weight. Each dose was calculated as milligrams of the free base and was dissolved in an appropriate volume of normal saline so that $S$ received $0.1 \mathrm{ml}$ of solution per $100 \mathrm{~g}$ of body weight. The Ss were injected $1 / 2 \mathrm{~h}$ prior to testing. At least 8 days intervened between successive methamphetamine injections, and all comparisons were made between the drug test and the two control tests prior to drug administration.

During training and testing, Ss were continuously observed on closed-circuit TV. allowing $\mathrm{E}$ to make note of gross behavior and observable convulsions.

Following the completion of the experiment, the animals were sacrificed and perfused. Histological sections stained according to the Luxol fast blue and cresylecht violet method were made to identify electrode sites.

\section{RESULTS}

Five of the nine Ss completed all phases of testing at all drug doses. Of the remaining four Ss, one was tested at three doses, two at two doses, and one at one dose prior to losing their electrodes.

Data for all Ss are summarized in Table 1. Average response rate per minute under drug treatment is expressed as a ratio of control rates. A score of 1.0 indicates no change. Scores greater than 1.0 indicate an increase in response rate during drug treatment.

\section{Low-Intensity Stimulation}

Eight of the nine Ss tested showed a significant increase in response rate at the lower intensities when treated with $0.5 \mathrm{mg} / \mathrm{kg}$ of methamphetamine $\mathrm{HCl}$. The one remaining $\mathrm{S}$ showed an increase which was not statistically significant. Except for one S (No. 97), who convulsed while self-stimulating at a dose of $2.0 \mathrm{mg} / \mathrm{kg}$, higher doses of 1.0 and $2.0 \mathrm{mg} / \mathrm{kg}$ produced greater increases in response rate at low intensities of stimulation. Four of the seven Ss engaged in stereotyped head-searching behavior or convulsed at a dose of $4 \mathrm{mg} / \mathrm{kg}$. It should be pointed out that when these same four Ss were treated on a subsequent occasion with the same dose of drug, but were not permitted to self-stimulate, they failed to show the stereotyped behavior. Since higher doses of amphetamines can elicit this stereotyped head searching, it seems possible that self-stimulation may potentiate the effects of methamphetamine.

\section{High-Intensity Stimulation}

When treated with $0.5 \mathrm{mg} / \mathrm{kg}$ of drug, six of the nine Ss showed a decrease in response rate at high intensities of stimulation, one S showed no effect, and two Ss showed an increase. At higher doses $(1.0,2.0$, and $4.0 \mathrm{mg} / \mathrm{kg}$ ), eight of the nine Ss decreased their response rates for high-intensity stimulation. The one remaining $S$ (No.97) significantly increased its response rate at all intensities with doses of 0.5 and $1.0 \mathrm{mg} / \mathrm{kg}$. 


\section{Zero-Intensity Control}

In the absence of drug, all Ss would cease responding by the end of the first $3 \mathrm{~min}$ of the zero-intensity condition. The second $5 \mathrm{~min}$ of the 10 -min period was characterized by no responding (range 0-1.2 average responses per minute). Doses of $0.5-2.0 \mathrm{mg} / \mathrm{kg}$ of methamphetamine increased resistance to extinction by significantly increasing response rate during the first 5 min (sign test, $\mathrm{p}<.001$ ). By the second 5 min of the test period, all Ss ceased responding at these doses. The $4.0-\mathrm{mg} / \mathrm{kg}$ dose produced data similar to lower doses in three of the seven Ss tested. The remaining four Ss failed to respond consistently at this or any other intensity at this dose of drug.

In general, doses of $0.5-2.0 \mathrm{mg} / \mathrm{kg}$ of methamphetamine shift rate-intensity functions to the left, toward lower intensities. This is illustrated for one $S$ in Fig. 1. Lower doses $(0.25 \mathrm{mg} / \mathrm{kg})$ did not consistently change rate-intensity functions. Between 0.5 and $2.0 \mathrm{mg} / \mathrm{kg}$, the shift in rate-intensity functions are dose-responsive, with higher doses producing greater shifts.

\section{Equated Response Rates at High and Low Intensities}

When response rates were equated at both high and low intensities of stimulation (14 paired comparisons), doses of 1.0 and $2.0 \mathrm{mg} / \mathrm{kg}$ of methamphetamine significantly increased response rates at low intensities while decreasing response rates at high intensities in 12 of the 14 comparisons. (An example is shown in Fig. 2.) A dose of $0.5 \mathrm{mg} / \mathrm{kg}$, while significantly increasing response rates at low intensities (10 times out of 11), did not consistently lower response rates at high intensities.

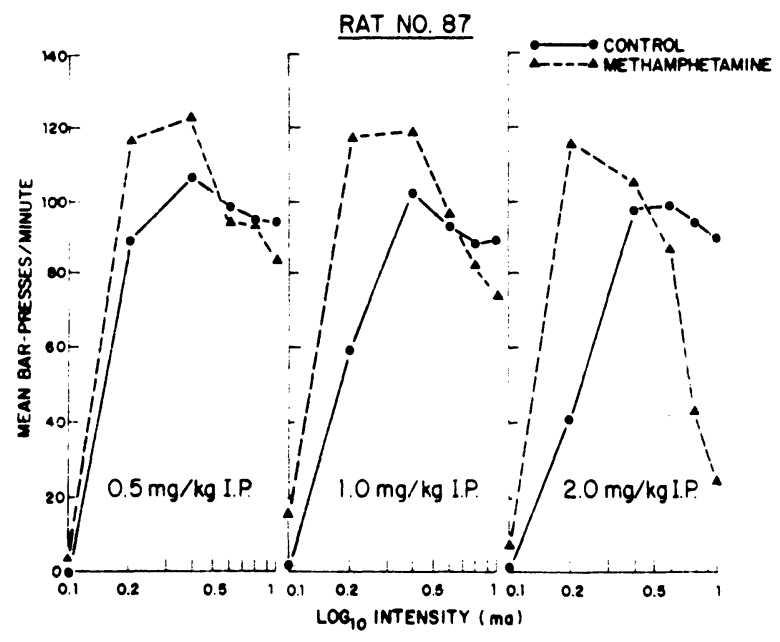

Fig. 1. Response rate for electrical brain stimulation as a function of stimulation intensity for a representative $S$ under placebo and methamphetamine conditions over three doses.

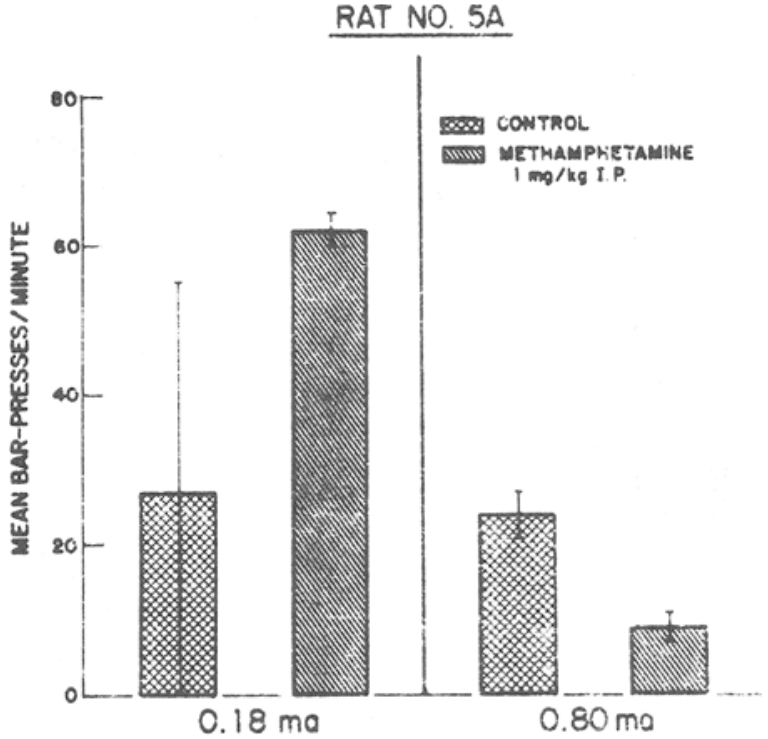

Fig. 2. Average response rates equated under placebo, at opposite ends of the intensity dimension, under conditions of placebo control and methamphetamine.

\section{Variability Around Threshold}

At very low intensities of stimulation (around the threshold for self-stimulation), response rates tend to be more variable than at higher intensities of stimulation. If amphetamines lower reward thresholds, then variability at these low intensities of stimulation should be reduced by amphetamine administration. Figure 3 plots the standard deviation of response rates as a function of stimulating intensity for one control and one methamphetamine $\mathrm{HCl}$ determination. Large standard deviations at low intensities are reduced by administration of methamphetamine.

\section{Histology}

For all Ss, the electrode tips were in or near the medial forebrain bundle between 1.0 and $2.0 \mathrm{~mm}$ lateral to the midline. Seven of the nine Ss had electrodes in the medial forebrain bundle between 1.0 and $1.5 \mathrm{~mm}$ above the base of the brain. lying between König and Klippel (1963) Planes A4110 and A2790. For S 83, the electrode was far anterior (Plane A6860), bordering on the medial forebrain bundle and nucleus interstitialis of the striae terminalis, while the electrode for S 97 was posterior and deep (Plane A2580), bordering on the medial forebrain bundle and substantia nigra, possibly involving the meninges.

\section{DISCUSSION}

The results of this experiment indicate that methamphetamine lowers neural reward thresholds. The 


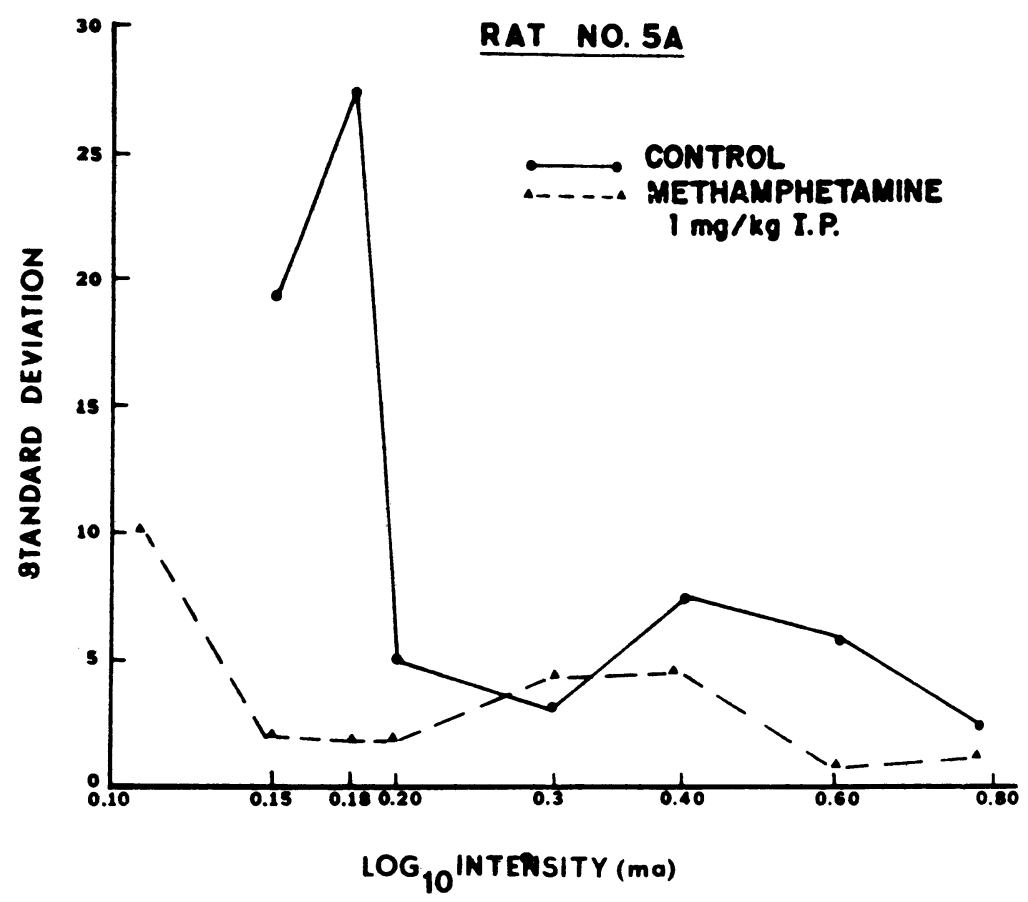

Fig. 3. Standard deviation as a function of stimulus intensity for a representative $S$ under conditions of placebo control and methamphetamine administration.

fact that equated response rates at opposite ends of the intensity continuum were changed in different directions with the drug in 12 of the 14 comparisons is in direct contradiction to the hypothesis that maintains that the effects of amphetamines on behavior maintained by ICS are a function of the control rate of responding (McMillan, 1968). This hypothesis, first suggested by Dews (1958), would predict that equated response rates should be changed in the same direction by the drug. The present data are in agreement with Stein's (1964a) contention that amphetamines lower neural reward thresholds (see Fig. 1).

An additional prediction that can be made from Stein's (1964a) hypothesis is that the variability of response rates at threshold intensities for self-stimulation should be reduced. A comparison of Figs. 1 and 3 reveals that, under control conditions, low intensities which are just capable of supporting self-stimulation yield highly variable response rates. Higher intensities produce less variable response rates. This is a general characteristic of thresholds for any intensity dimension: subthreshold intensities produce no or few responses and hence little variability; intensities well above threshold consistently produce responding and hence little variability; but intensities at threshold produce maximum variability. If amphetamines lower neural reward thresholds, then drug treatment should reduce variability at intensities which, under control conditions, are at threshold. The results of this experiment confirm that prediction.

\section{REFERENCES}

Bower. G. H.. \& Miller. N. E. Rewarding and punishing effects from stimulating the same place in the rat's brain. Journal of Comparative \& Physiological Psychology, 1958, 51, 669-674.

Dews, P. B. Studies on behavior: IV. Stimulant actions of methamphetamine. Journal of Pharmacology \& Experimental Therapeutics, 1958, 122. 137-147.

Dews. P. B., \& Morse, W. H. Behavioral pharmacology. Annual Review of Pharmacology, 1961, 1, 145-174.

Horovitz, Z. P., Chow, M., \& Carlton, P. I. Self-stimulation of the brain by cats. Technique and preliminary drug effects. Psychopharmacologia, 1962, 3, 449.

König, J. R. F., \& Klippel, R. A. The rat brain: A stereotaxic atlas of the forebrain and lower parts of the brain stem. Baltimore: William \& Wilkins, 1963.

McMillan, D. E. The effects of sympathomimetic amines on schedule-controlled behavior in the pigeon. Journal of Pharmacology \& Experimental Therapeutics, 1968, 160. 315-325.

Olds. J. A preliminary mapping of electrical reinforcing effects in the rat brain. Journal of Comparative \& Physiological Psychology, 1956, 49, 281-285.

Olds, J. Higher functions of the nervous system. Annual Review of Physiology, 1959, 21, 381-402.

Reynolds, R. W. The relationship between stimulation voltage and rate of hypothalamic self-stimulation in the rat. Journal of Comparative \& Physiological Psychology, 1958, 51, 193-198.

Stein, L. Amphetamine and neural reward mechanisms. In $\mathrm{H}$. Steinberg, A. V. S. DeReuct. and J. Knight (Eds.), CIBA Foundation symposium on animal behavior and drug action. London: Churchill, 1964a.

Stein, L. Reciprocal action of reward and punishment mechanisms. In R. G. Heath (Ed.), The role of pleasure behavior. New York: Hoeber, 1964b.

Stein, L. Self-stimulation of the brain and the central stimulant action of amphetamine. Federation Proceedings, 1964c, 23, 836.

(Received for publication December 11. 1972: accepted January 8. 1973.) 